\title{
University Reform in Germany
}

\section{W. Meyerhardt}

To cite this article: M. W. Meyerhardt (1917) University Reform in Germany, The Pedagogical Seminary, 24:2, 149-179, DOI: 10.1080/08919402.1917.10534724

To link to this article: http://dx.doi.org/10.1080/08919402.1917.10534724

册 Published online: 30 Aug 2012.

Submit your article to this journal 2

III Article views: 5

Q View related articles $\sqsubset$ 


\section{THE \\ PEDAgOgICAL SEMinary}

$\therefore$ Founded and Edited by G. Stanley Hall

$\begin{array}{lll}\text { Vox. XXIV JUNE, } 1917 & \text { No. } 2\end{array}$

\section{UNIVERSITY REFORM IN GERMANY*}

By M. W. MEYERhardT

The teaching force of the German universities may be roughly divided into ordinary, and non-ordinary teachers. The Ordinary Professors (O.P.), either with regular professorship, which is fixed and contimuous, or with personal professorship, which expires with the occupant, constitute the nucleus of the teaching staff. They are appointed by the reigning Sovereign upon the motion of the ministry who, as a rule, take into consideration the proposals by the faculty of the names of three men thought suitable for the position; but the government is not bound to confine its choice to these names. In addition to a salary paid by the State, graded according to length of service until a maximum is reached, they draw honoraria for their private lectures and fees for graduation, and other examinations. In the administration of the inner affairs of the universities only O.P., generally speaking, have a right to vote as occasion presents itself. From their midst the rector of the university is elected, and from their number also proceeds the delegate of the university chosen as its representative to the Diet of the State.

The non-ordinary staff (N.O.) consists chiefly of Honorary Professors, (H.P.), Extra-Ordinary Professors, (E.O.), and Private Docents (P.D.).

H.P. have the rank of E.O., but have neither teaching com-

* This paper presents in substance the first chapter of a study entitled "University Organization and Reform." The other chapters discuss the universities of Austria, Switzerland, Bulgaria, Great Britain and the Overseas Dominions, France, Russia, Italy, Spain, Greece, Sweden, Norway, Denmark, Japan, and the United States. 
mission and salary, nor a definite duty as instructors. In most cases they are older men who have made a name for themselves and in this way are publicly brought into independent connection with a university.

E.O. are either " etatsmässig " or " non-etatsmässig," that is to say, with or without a fixed salary. The former are appointed permanently at a fixed salary which is periodically increased until a maximum is reached. They have a teaching commission for a certain subject or a group of subjects, usually to complete the instruction in the chief branches of study or to represent subjects for which as yet no ordinary professorship has been created. Although sometimes in charge of important sub-departments, their position is that of an associate or assistant professor and as such, with few exceptions, they have neither voice nor vote in the administrative affairs of the university or of the faculty. If non-etatsmässig, they draw no salary but sometimes have a teaching commission and, in that case, receive a small remuneration.

P.D. are scholars who, on the fulfilment of the requirements of habilitation, have been extended the privilege of teaching in a university. But the bestowal of the venia legendi signifies merely admission into the teaching body of scholars and not into the State's official corps of instructors. Hence his lecture fees are the sole remuneration which a P.D. may expect. Teaching commissions, given only rarely and in exceptional cases, are limited and involve no claim to permanence. As a teacher the P.D. is, nominally at least, on equal terms with the professors. He has the use of lecture rooms and laboratories and his lectures and exercises are officially announced. Formal enrolment of students in his courses is accepted as regular work, but they are confined to the subject for which the P.D. has qualified.

The historical predecessor of the P.D. was the magister legendus of the early universitas. In the times of the studium generale, and also later when that title had been absorbed and universitas designated the institution of learning as such, every student, by virtue of his degree, became a member of the faculty by whom it was conferred. The bestowal of the master's degree included the venia legendi and in some instances involved the obligation to teach at the mother university for a period of two years. Though self-preservation soon made certain distinctions imperative, in principle this right of the Graduate to lecture everywhere without special permission remained with him for several centuries. The university of Halle, for example, founded in 1694, reiterated in its statutes his right to all the functions of the professor as established by law or by custom. His position, however, never an enviable 
one, in time became so precarious that in the first half of the eighteenth century not many followed the calling. An academic career at its best offered then but few attractions. The middle classes were poor, and bright and promising students from these strata of the German people aspired to positions more lucrative than the breadless art of teaching in the universities whose reputation had sunk low and who were completely overshadowed by the newly founded academies.

Probably for similar reasons the number of extra-ordinary professorships was not large at that time. This position had come into vogue during the seventeenth century when various Sovereigns; in addition to regular professors, called to their universities professors "extra ordinem." They received no fixed salary but usually a small emolument from the private exchequer. They were excluded from participating in faculty affairs and had no voice in the autonomous administration of the university. Their position was desirable chiefly because it was apt to be a stepping stone to an ordinary professorship whenever a vacancy occurred.

\section{Gradual InCREase of the N.O.}

Available statistics show that in the second half of the eighteenth century the E.O. and P.D. formed a negligible part of the university teaching staff. In 1758 the N.O. constituted $24.8 \%$ of the teachers in all German and Austrian universities. For forty years this percentage remained nearly stationary so that in $1796,26.8 \%$, or a trifle more than one fourth of the force were N.O. But the next century saw a great change in these proportions. The N.O. increased so rapidly as in time to equal and finally greatly to surpass the O.P. in number. The relatively greatest increase occurred after 1880 . The ratio in the German universities was in

$$
\begin{aligned}
& 1880 \ldots \ldots \ldots \ldots \ldots \\
& 1890 \ldots \ldots \ldots \ldots 121 \text { N.O. to } 100 \text { O.P. } \\
& 1900 \ldots \ldots \ldots \ldots 140 \text { N.O. to } 100 \text { O.P. } \\
& 1906 \ldots \ldots \ldots \ldots 144 \text { N.O. to } 100 \text { O.P. } \\
& 1914 \ldots \ldots \ldots \ldots 167 \text { N.O. to } 100 \text { O.P. }
\end{aligned}
$$

Whereas, accordingly, at the beginning of the eighteenth century the ordinary teaching force represented the university in number as well as in fact, at the beginning of the twentieth century the situation is almost reversed, so that in some of the larger universities the E.O. or the P.D. are more numerous than the O.P.

Factors of both an objective and a subjective nature are held to be responsible for these conditions. In the first place, 
the number of O.P. was not increased sufficiently to keep step with the increase in the number of students. Then again, an inner need for a larger teaching force made itself felt, in satisfying which the increase in ordinary professorships proved entirely inadequate. It grew out of the enlargement of the subject matter, specialization, and the consequent formation of new and independent sub-departments of various sciences. To create ordinary professorships for all these divisions was obviously inexpedient. But since the teaching of each required the knowledge of a specialist, the number of N.O. grew. In the meantime, subjective factors contributed to the same result. While in the eighteenth century literary pursuits or the diplomatic service were generally given the preference to an academic career, sentiment changed in the nineteenth century and thereby caused the supply of academic teachers to exceed the demand. The lure of academic freedom and independence, the long vacations, the privilege to arrange working hours to suit one's convenience, and the opportunities for research prove enticing to many, not to mention the preferred social status of the academic teacher and the nimbus that surrounds the title of "Professor," which acts on the ambition and vanity of certain classes as a power of irresistible attraction. On the other hand, the overcrowding of all professions, the inevitable long waits for positions, and the immediate need of some sort of an income, drive many to chancing an academic career. Thus, inducements, often diametrically opposed, combine sometimes in creating motives for embarking upon the academic career and thereby produce an oversupply of younger teachers.

An analysis of the social origin of the N.O. sheds further light on the phenomenon. Professor Eulenberg (5), dividing the parental vocations into five larger categories, ascertained in 1908 by means of a questionnaire that the higher commercial pursuits and the learned vocations furnished over two thirds of the academic after-growth, so called. The fathers of over $37 \%$ of the N.O. were found to be land-holders, manufacturers, or merchants. They comprise the well to do classes. They have grown rich and their sons can afford a breadless scientific career, a fact, of course, which does not preclude the possibility of their being turned in that direction by a psychological factor, founded in the general spirit of mental activity and agility that is apt to prevail in their homes. In the group comprising professional and related vocations which demand a higher education, the university teachers, as is to be expected, were most numerous. Social heredity, expectation of aid in habilitation and promotion, and of a general smoothing out of affairs, probably account for it. Next came 
the physicians where the parental milieu most likely played an equally important rôle. A relatively large number was furnished by the higher State-officials, with whom the opportunity for the son to make a name for himself, and also the social advantages of an academic career might have been the determining factors. The showing made by the small capitalists confirms the conclusion that the learned and the well to do furnish the bulk of the academic aftergrowth, and that the contribution is small when the parental vocation tended to create a mental atmosphere which diverted attention from an academic career.

\section{Distribution of the N.O.}

The non-ordinary force does not form an inner homogeneous unity but is characterized by typical similarities and differences which correspond to general conditions. The Prussian, the non-Prussian and the Austrian institutions form distinct groups; the large, the medium, and the small universities show noteworthy differences; and again, the distribution among the single faculties is not uniform. The relatively large proportion of N.O. in Prussia and in Austria has its cause chiefly in the abnormal conditions which obtain in Berlin and Vienna. The bulk, namely, of the N.O. is found in the larger institutions, whereas the smaller ones are avoided. This is largely due to the fact that larger cities, such as Berlin, Vienna, Munich and Leipsic, present better opportunities for supplementing the income from academic teaching with that from private occupations. Or the opposite sometimes is the cause. A well to do P.D. prefers the comforts and attractions of life in the metropolis. Indeed, it is not an unheard of occurrence that a P.D. in one of the larger universities, with a lucrative field of activity, is loath to be transferred to a smaller institution, even with promotion in sight.

As to the faculties, the academic after-growth in theology and in law is not numerous, and that for obvious reasons. The lack of differentiation within the sciences, the exclusiveness of the single branches, and the dogmatic treatment of the subject matter are not very conducive to stimulating scientific research. Entirely different, however, are conditions in the medical faculty where the ideal of individual instruction is approached. The ratio of N.O. to O.P. in this faculty is more than 3 to 1 . Although this large number of N.O. is desirable, it is nevertheless to be pointed out that many of them have but loose connection with the university. In some cases habilitation is obtained by physicians chiefly in the hope of improving thereby their medical practice. Leniency in the 
requirements of habilitation is also held to be responsible for the overcrowding. Similar, and for much the same reasons, are conditions in the natural sciences where, particularly in chemistry, the growth in numbers of the N.O. seems to be out of proportion to the requirements. In history and philology, owing to many sub-divisions of the sciences and to specialization in many directions, the number of O.P. is large and the after-growth also is, and may be, large without the supply exceeding the demand, more particularly since for many of the smaller sub-divisions no ordinary chairs have been established.

Looked upon as indicators of the chances for promotion the figures show that for each 3 O.P. in theology and in law there are two prospective successors, whose chances, accordingly, are fairly good. In history, where the numbers are nearly equal, advancement depends on the length of life of the O.P. Least favorable appear the chances for promotion in the medical faculty where there are 3 , and in the natural sciences where there are 2 candidates for each prospective vacancy. But fortunately all this is but figuratively speaking true. As a matter of fact, the circle within which the actual selection for advancement occurs is much smaller than the absolute numbers indicate. This is made. evident by even a casual analysis of

The Inner Composition of the N.O. Staff.

Looked at from within, the N.O., from the view-point of personal position and ambition, may be divided into three general groups. (1) N.O. with whom teaching, either from necessity or from choice, is but a secondary occupation. As a rule they occupy another position from which a fixed income is derived. Such are directors of museums or of statistical bureaux, superintending physicians of state or city hospitals, librarians, clergymen, etc. Their presence in the university is held to be wholly desirable. A permanent contact with non-academic conditions of life is apt to result in the introduction of a new and probably wholesome point of view, since only the better qualified know how to combine in this manner their scientific interests with an improvement of their financial condition. To be sure, there is the disadvantage of their subordination to the external influences of politics, church, and other higher authorities, which robs them in part of that freedom and independence so inseparable from the position of the academic teacher. This fact, however, requires no serious consideration. Advancement to an ordinary professorship is in their case improbable, if not impossible, chiefly because 
their necessarily limited academic activity precludes achievement of that distinction of scientific performance which is a condition of promotion. Hence they are hardly to be counted in as academic after-growth. (2) The free lances, or those who for certain reasons, voluntarily or involuntarily, have to renounce all aspirations to an ordinary professorship. Among them are men who for one reason or the other were prevented from obtaining the venia legendi until late in life. Perhaps they were teachers or officials elsewhere, thirsting for the greater freedom and more extended sphere of activity at a larger university. Possibly they have only lately been rendered financially independent and thereby enabled to give their whole time to scientific research. Others there are, full of scientific enthusiasm, who are satisfied to make a living somehow, supplementing their lecture fees by an income derived from tutoring or from authorship. All these do not care to be identified with the official organization of the university, including the drudgery of administrative work. Here also belong the so-called "outs" of each science: In theology, the free thinkers of an orthodox faculty; in medicine, the representatives of some special school; in the natural sciences, the neo-vitalists; in philosophy, the followers of Hegel, Schopenhauer, von Hartmann, or Avenarius ; in national economics, the disciples of Manchester or of scientific socialism; in a word, all those outside of that realm of science which is officially recognized by way of a teaching commission. All in all, a mixed gathering of scholars this, who indeed contribute much to the life of the German university, giving it color and shading, but who are hardly in line for an ordinary professorship, that official position meant to be entrusted only to those who cultivate the commonly accepted branches of learning to be transmitted to the future officials, physicians, judges, teachers, etc. (3) The last and numerically strongest group, the regular docents; namely, those who mean to ascend the academic hierarchy; first, to be promoted to an extraordinary professorship without or with teaching commission and, eventually, to reach the final goal in the form of a full professorship. They constitute the real academic aftergrowth and, as will be made more evident, by force of the extensiveness and importance of their activities are an integral part of the teaching staff. Yet, their participation in the inner administrative affairs of the university is insignificant, and again, not an inconsiderable part, it is claimed, is retained in this unofficial position without being less useful or necessary for university instruction as a whole than the ordinary professors are. 


\section{The Movement for Reform}

Rumblings of dissatisfaction and whispers of the need of reform have for sometime been going the rounds of the nonordinary teaching staffs of many of the universities. But, while convinced that prevailing conditions were the sluggish resultant of tradition, prejudice, and inertia, rather than the live product of clear and far-sighted vision, the majority preferred to remain silent. They adapted themselves to the administrative machinery as they found it, satisfied with the wisdom of the adage that discretion often is the better part of valor. In 1907, however, a few of the more venturesome decided that the time for action was rife. A call to all universities where the German tongue is spoken was issued by a preparatory committee, and the Fall of that year saw at Salzburg the first German university teachers convention.

Discussion turned to a variety of topics. Since reform, like charity should begin at home, the shortcomings of academic teachers were given an airing. On the other hand, speakers deplored the fact that the well founded system of autonomous administration under State supervision had been permitted to deteriorate into that of a bureaucratic hierarchy. Attempts of government interference in matters which always had been functions of the university were criticised as demoralizing, tending to lower the status of university teachers, and even threatening to render freedom of teaching but a hollow name. Under these conditions, it was pointed out, the problem which confronted them involved not the mere question of a readjustment of a few personal grievances but the attainment of an ideal; hence, further apathy might easily be construed as emanating from the lack of an adequate sense of professional honor. Concerted action was urged and, organization being effected, it was voted to co-operate in the establishment of an annually recurring convention and in the formation of local organizations in all cities where universities are located. Through the efforts of an executive committee a number of local organizations soon came into existence and, in 1909, the E.O. in nearly all Prussian universities had locally combined and under the name of "Association of Prussian E.O." formed an inter-institutional organization. The P.D., being left to shift for themselves, established local organizations of their own, but at a conference in Halle in 1912, to which all other non-ordinary organizations then in existence had been invited, effected a second inter-institutional combine under the name of "Association of German P.D." Finally, in 1912, all local organizations in the non-Prussian universities, where the E.O. and P.D. had made common cause, united 
with the German P.D. in a larger body known as "Union of German N.O. Organizations' which, accordingly embraces all German N.O. with the exception of the Prussian E.O. Headquarters are maintained at Halle from where annual reports are issued of which, however, but two have thus far appeared.

\section{The Argument of the Advocates of Reform}

Notwithstanding changed conditions, State authorities and faculties, the directive forces of the university, still persist in regarding the position of the E.O. as, what historically to be sure it is, an intermediate or transitionary one. This is held to be the comprehensive cause of the unsatisfactory conditions. The rest is but a bill of particulars.

Proof that the position of the E.O. is in reality no longer a waiting station is adduced from various directions. There are many reasons for falling by the wayside en route to the circle of the select. A teacher may represent a discipline for which from financial reasons no full professorship has been created; his branch may be too specialized and remote to admit of the establishment of a chair; or it may be so unique as to render inexpedient its perpetuation owing to the difficulties to be encountered in the attempt to secure a suitable successor. All these are apt to be permanently retained in the position of an E.O. Again, in several branches the after-growth is so numerous that a number of candidates are available for every vacancy and, since outsiders are occasionally extended a call, individual chances for promotion are correspondingly small. External influences, such as matters of creed or adherence to some definite school of thought, sometimes modify, favorably or unfavorably, the degree of eligibility. Lastly, the fact is to be mentioned that advancement to an ordinary professorship comes to the average teacher only relatively late in life.

On the other hand, the work of the E.O., it is asserted, qualitatively as well as quantitatively is equivalent to that of the O.P.; his responsibility, when occupying the position of manager of an institute, seminary, or clinic, of ten equals that of an O.P.; his importance also is recognized by the State, since E.O. are pressed into service in the State examinations. Yet, in all which concerns rank, salary, corporate rights, and official influence in matters of instruction and administration, the E.O. is dealt with as occupying a minor position, so much so that in some instances he has retained even the official robe of the P.D. 
The Government's Point of View of the Position of THE E.O.

Officially, the N.O. claim, an extra-ordinary professorship is regarded as a subsidiary or provisional position. Its function is to supplement or to complete instruction. It has been thus defined on various occasions in the discussions of the diet and by ministers of education: "Whenever a new discipline springs up, to start with, an extra-ordinary professorship is created, and later, when this discipline has become fixed, when its general importance can no longer be questioned, and particularly when a suitable man for the position has been found, an ordinary professorship is established. Naturally, this step also depends largely on considerations of a financial nature." Hence, when the number of students in a department increases very rapidly and the scientific work grows to such an extent that one teacher can no longer master it, it is the custom of the authorities to place an E.O. with teaching commission alongside the O.P. And similarly, in order to estimate the range and importance of a new branch of science, an E.O. with special teaching commission is at first put in charge.

Consonant, furthermore, it is pointed out, with this official conception of the position of the E.O. are his emoluments. A few data substantiate this. Of 155 Prussian E.O. who in 1909 answered an inquiry,

(a) 30 were outside the official salary provisions, but of these 19 received a remuneration of from $\$ 150$ to $\$ 750$ annually.

(b) 105 came within the official salary provisions which since 1909 are in Prussia as follows: Initial salary, $\$ 650$; after 4 years, $\$ 775$; after 8 years, $\$ 900$; after 12 years, $\$ 1,000$; after 16 years, $\$ 1,100$; after 20 years, $\$ 1,200$. Professors who derive an income from extra-academic activities remain at the initial salary. Those who draw less than $\$ 300$ in collegium fees are paid the difference to make up that amount; on the other hand, there is a deduction of $25 \%$ from all fees over $\$ 750$, and $50 \%$ from all fees amounting to more than $\$ 1,000$. An allowance for rent goes to all who are "etatsmässig."

(c) 20, who were division superintendents, received the salary of an E.O. purely in their capacity as State officials. Academically their position was entirely titular, could be terminated at six months' notice, and entitled them to a pension only under the general code.

Significant, finally, in stamping the position of the E.O. 
as a subordinate one, are the definitions of his status in the statutes of various universities. Those of the university Bonn, for instance, expressly state that to an extra-ordinary professorship shall be promoted " the more eminent and rising young academic docents, partly in order to encourage them in their chosen profession, partly to have them assist the O.P. and supplement his work." And this conception dominates the constitutions of all universities. The administrative rights of the E.O. are conspicuous by their absence; his participation in matters concerning instruction is limited and, being regulated chiefly by custom, is permissive rather than mandatory.

\section{The Facts in the Case}

The contention that the N.O. occupy chiefly positions in the newer, more remote, the relatively unimportant branches of science, and that in most cases these are but temporary positions, is disproved by an analysis of (1) the teaching commissions of E.O., (2) the activities of the N.O., (3) the time required for preparation, the waiting periods and the age of the N.O., and (4) the average age of the O.P., which suggests the need of a rejuvenescence of the official teaching force.

\section{Teaching Commissions of the E.O.}

Of 150 Prussian E.O. outside of Berlin, in 1909, 23 E.O., or less than $1 / 6$ had no teaching commission, due to the fact that mere titular promotions are rare.

27 E.O. had a teaching commission designated as "for the purpose of supplementing the activities of the department O.P."

14 E.O., or less than $10 \%$, had a teaching commission for a special discipline, subordinate to the department O.P.

43 E.O. had a teaching commission for a substantial discipline and in many cases were independent of the O.P., the commission being worded "to represent in lectures and exercises" theoretical physics, children's diseases, etc.

43 E.O. had a teaching commission which in no way differed from that of an O.P.

In other words, of the E.O. with teaching commissions more than two thirds had full charge of their department or subdepartment. That a goodly number of these teaching commissions were equivalent to those of O.P. is indicated by the fact that certain disciplines of E.O. in smaller universities are in the larger institutions in charge of an O.P., and again that the duties and responsibilities of many of these E.O. do not differ from those of an O.P. 
In 1907, for which year full data are available, about the same ratio otbained, approximately two thirds of the E.O. in all German and Austrian universities having larger or smaller teaching commissions. Their general importance for instruction is revealed by a brief review of

\section{The Activities of the N.O.}

The lecturing activities of the E.O. and P.D. combined amounted during the summer semester of 1907 to over two fifths of the total number of lectures delivered in all the universities. In the natural sciences the N.O. assumed nearly one half of the total lecturing activities, and in medicine the number of weekly hours of the N.O. actually surpassed those of the O.P. Some of the causes of this state of affairs have already been referred to. Foremost responsible is the growth of the subject matter of science, the introduction of new disciplines, and the development of new branches by specialization, to cover which the number of ordinary professorships proved inadequate. A second reason is that the increase in the number of O.P. has not kept step with the growth of the student body. There were in round numbers for each O.P. in 1860,20 students; 1880,22 students; 1900,29 students; 1910,43 students.

And thirdly, promotions to an ordinary professorship in recent years occurred largely in the philosophical faculties, whereas in the so-called upper three faculties the number of O.P. was in some instances actually reduced. Parallel chairs in the latter are rare and, as a consequence, O.P. often lecture to audiences of 200 students or more.

However, in addition to the lecturing activity, an important development in another direction must be considered, namely, individual and personal instruction. Mass instruction by the lecture method is not everywhere feasible. Particularly in medicine and in the natural sciences great weight is necessarily placed on institute and laboratory work, and this individualized form of instruction is beyond the power of one man. From 10 to 15 may be said to be the maximum number of students whose work one instructor is able to profitably supervise. Assistants are required and lately have been employed in increasing numbers, in part for reasons other than the one just mentioned. The celebrated and much sought after O.P. has more important work than that of instructing beginners and, again, a younger man sometimes is really better qualified to teach those to whom he stands personally closer, and to teach that which requires more recent practice than the older men usually can boast of. Here then a great 
field is open to N.O. and we find, as a consequence, in medicine, a small army of E.O. and P.D. occupying positions as assistants, chief-physicians, prosectors, institute-managers, etc., and in the natural sciences, over $30 \%$ in positions of similar importance.

From a qualitative point of view likewise it is necessary that the O.P. have assistance. The student body has not only increased in size but of late has become more heterogeneous, being composed of graduates of three kinds of institutions with wholly distinct methods of preparation. Not a few are attending the universities without being immatriculated. Male and female teachers, agricultural students, authors, journalists, and others, many of which would derive little benefit if condemned at once to an attendance of the advanced courses by O.P. and who are better served by first subscribing to introductory lectures and courses offered by assistants. Then again, the generally recognized schools of thought and the officially approved views do not appeal to all, yet the true meaning of the term "universitas literarum" implies the obligation of presenting all sorts of views, while the principle of freedom of teaching involves the right of all needs being satisfied. Here also the N.O. steps into the breach and, by introducing a younger force and a new point of view, becomes a wholesome competitor. Lastly, some entirely new tasks have of late come within the scope of academic activity. Merchants, factory managers, workers of all kinds, and even women, are now admitted to the most advanced courses of vocational education, and courses are offered which aim at a refreshing and bringing up to date of the knowledge of those who are permanently occupied with their life's work. Review courses for physicians, continuation courses in political economy, vacation courses for teachers and theologians, technical courses in the natural sciences, and advanced theoretical courses for superintendents and other officials of the great mercantile and industrial establishments, have in recent years become fixed innovations at some of the universities. All these facts, it is held, combine in permanently raising the utility threshold of the non-ordinary teaching force and, by the extensiveness and variety of their nature, tend to show that the academic after-growth has not only acquired a new and inner import, but has assumed specific and independent tasks which are mentally or physically beyond the range of activity of the ordinary professors. 
Time of Preparation, Waiting Periods, and Age, of THE N.O.

An analysis of the average age of the present N.O. and a comparison of their age at the different preliminary and intermediate stations with the corresponding age of the present O.P. impels the question, it is pointed out, whether the time is not rapidly approaching when an extra-ordinary professorship can really no longer be regarded as a steppingstone to promotion.

Statistics, applying to 1907 , show that the O.P. obtained the Ph.D. degree at an average age of 23.7 years, the N.O. at about 24.5 years; in other words, that the average age of promovation gradually has been pushed forward. Habilitation, the next step in an academic career, was obtained on an average by the O.P. at 28 , after 4.2 years of preparation; by the E.O. at the age of 30.7 years, after 5.4 years of preparation; by the P.D. at 30.7 years, after 6.1 years of preparation. These figures indicate that the time of preparation for an academic career is steadily increasing.

The O.P. had attained the grade of E.O. at an average age of 32.4 years, after averaging 4.3 years as P.D.; the E.O. had been promoted to that position at an average age of 36.5 years after averaging as P.D. 6.6 years, or 2 years longer than the O.P. If one considers that the average age of the P.D. in 1907 was over 38 years and that they had occupied this position already for an average period of upward of 6 years, it does not seem unreasonable to assume that in their case the intervening period to promotion will again be considerably prolonged.

The O.P. had reached the full professorship after a waiting period of approximately 4.5 years at an average age of about 37, which means that they had reached the goal at an age when those who were then E.O. had been appointed to the lower office. Since the average age of the E.O. was somewhat over 46 , and about $10 \%$ of the E.O. were over 60 years of age, and since by a prolongation of the waiting periods at the intermediate stations the prospects of ultimate advancement to a full professorship become more and more remote, it seems indeed necessary to pause and reflect if it is still permissible to speak here of an after-growth.

It is, of course, true that occasionally a young man is appointed to a full professorship, but on the whole, it would appear, the figures above can be trusted to describe the actual conditions. They are confirmed by the following calculation: In 140 promotions to an ordinary professorship during the three years from 1905 to 1908 the average age of the new 
appointees in all Prussian universities was 41.7 years, and that of 55 Austrian appointees in the same period was 42.3 years. These figures show that these promotions occurred on the average 5.4 years later than the corresponding promotions of all O.P. holding office in 1907.

The Need of a Rejunenescence of the O.P.

The average age of all O.P. increased in the space of half a generation just two years. In 1890 it was 51.5 years; in $1907,53.5$ years.

In $1890,32 \%$ were below 45 ,

$48 \%$ between 46 and 60 ,

$20 \%$ were over 60 .

In $1907,23 \%$ were below 45 ,

$52 \%$ between 46 and 60 ,

$25 \%$ were over 60 .

This table serves to show how the increase of the average age was brought about. The percentage of O.P. above the age of 45 has increased from $68 \%$ to $77 \%$; that of the O.P. below the age of 45 has decreased from $32 \%$ to $23 \%$. In other words, the reason for the increase of the general average is the decrease or total disappearance of the younger O.P.

That this state of affairs is pointed to by the advocates of reform as being unfortunate for instruction as well as for science itself, it is needless to tell. They go so far as to assert that, in view of the possible ascendency in international competition of younger nations with fresher forces and with new ideas, it is apt to prove fatal. A teaching staff or a faculty composed mainly of old professors incurs the danger of becoming stagnant by its disdain of innovations. Confronted by the authority vested in a celebrated name, a departure from accepted doctrines is rarely attempted and is apt to be repudiated as an unwarrantable intrusion upon a privileged domain. Students, in view of the O.P.'s position of absolute power, are prone to preferably choosing those courses which conform to his personal opinions and methods, and in the particular disciplines which he favors. Under such circumstances, new methods and new directions of thought are strangled at the start, and many a promising idea finds an untimely end.

It is also not beyond the range of possibility that even an eminent scientist, rendered less active by old age or infirmity, may thereby fall behind the times. In such a case the whole branch of studies in his charge may, and has been known to, lie prostrate for years in that particular university and the number of students steadily to decline. This could easily 
have been avoided if a second professor with equal authority had stood by his side.

\section{Some Statistics up to Date}

Statistics, compiled by the writer, show that during the seven year period extending from 1907 to 1914, which may be said to embrace the time of active agitation for reform, the increase in the number of O.P. amounted to 5\% against an increase of $20.1 \%$ in the number of N.O.; $5.1 \%$ for the E.O. and $31 \%$ for the P.D. These figures indicate that no appreciable changes, other than those stamped by custom as normal growth, seem to have occurred in the make-up of the teaching staff of the universities, unless one cares to point out that the P.D. appear to have increased more rapidly than ever before.

That the authorities, in the appointment of teachers, have maintained the even tenor of their ways is also suggested by other facts :

(1) The average age of both, O.P. and E.O., has increased since 1907. But, while that of the former did so but slightly, namely from 53.5 to 53.8 years, the E.O. of 1914 with an average age of 47.25 were more than a year older than the E,O. of 1907.

(2) The ratio of the average number of students to O.P., which in 1910 was 43 to 1 , has increased so that in 1914 it was 50 to 1 .

(3) Figuring by faculties, there was in the period from 1907 to 1914 an increase of the number of

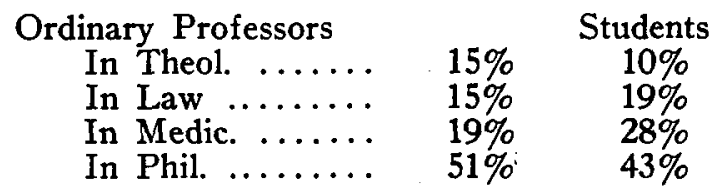

In the theological faculties the percentage of increase in the number of O.P. was relatively large. This is to be explained only by the fact that the division of this faculty in several institutions into a protestant and catholic section makes virtually parallel teaching staffs necessary.

The large increase in the number of O.P. in the faculties of law most likely was unavoidable since, even as now constituted, their allotment of O.P. is small, if their large percentage of students is considered. This displacement, of course, is justified; for instruction in law is carried on chiefly by the lecture method and in seminaries where one O.P. may supervise a relatively large number of students. High, nevertheless, 
as the percentage of increase was, it did not fully meet the requirements. While in the theological faculties the number of E.O. had remained stationary, in law it was found necessary to add over $25 \%$. This fact, if one considers that the P.D. in law also increased by nearly $30 \%$, not only suggests that the work of the N.O. is figured on by the authorities as a substantial factor in instruction but gives room to the suspicion that E.O. sometimes fills places for which ordinary professorships should be created.

The same is true in the medical faculties. Here the O.P., after an increase of $5 \%$, constituted in 1914 but $19 \%$ of the total ordinary force, and that in spite of the fact that $28 \%$ of the student body are medical students, and that in medicine, with its institute, clinical, and laboratory work, the need of instructing and supervising small groups of students renders imperative the presence of more teachers than in theology or law. These teachers to be sure are forthcoming, but in the capacity of E.O. who, having been increased by $10 \%$, now outnumber the O.P., and of 124 P.D. who were added to the 426 P.D. active in 1907.

That in philosophy and the natural sciences the exigencies of instruction demanded more ordinary teachers than were installed is shown by the increase of nearly $30 \%$ in the number of P.D., a fact which leaves no other conclusion than that the government side-stepped paying for something which it knew it could get for nothing.

That this apparently is the policy which is being pursued is further demonstrated by the fact that in the large institutions, but also in some of the smaller ones, such as Freiburg, Heidelberg, and Jena, the attempt to compensate for the inadequate number of O.P. by a disproportionately large number of E.O. is quite obvious. And the argument is clinched by figuring the average number of students for each teacher by faculties. In doing so, we find in 1914 for each O.P. in

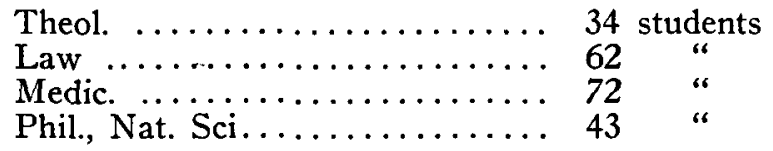

The numbers become more equal when the number of students for each one of the O.P. and E.O. combined is computed, namely,

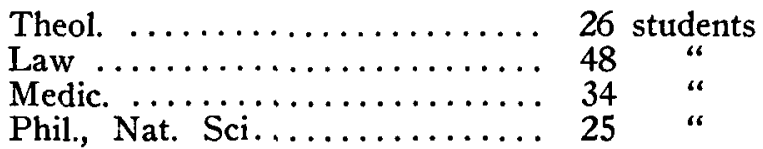


They become reasonable only by also including the P.D., namely,

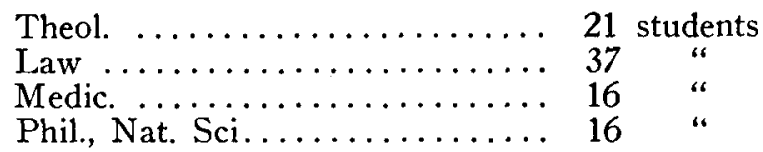

There can be no doubt that in the faculties of medicine the absence of any considerable part of the N.O. would seriously impair efficiency of instruction. Nor could they be spared in the natural sciences.

The inadequacy of the number of O.P. in the larger universities, even for the lecture form of instruction is so marked that, of late, members of the student body have taken a hand in the discussion of the problem, their chief point of complaint being the resulting lack of inner contact between professor and student. The idea of the lecture form of instruction as the chief implement of university education, one writer suggests, is a mistaken one anyway. The lecture is overemphasized. "It should be superseded by the general discussion of topics, consultations and conferences, in brief, by the substitution of the personal equation for the dead letter."

Unfortunately, however, just those forms of instruction in which personal contact is supposed to be most essential, the seminaries for instance, seem to furnish the most glaring examples of the evils which present conditions give rise to. A good illustration of these is found in the description of a concrete case by Professor Bernheim of the University of Greifswald, at one time its Rector, and now O.P. of history.(2)

After stating how Leopold von Ranke was the first to establish these seminaries for a limited number of his best and most advanced students, - that his successors perpetuated the practice so that finally they became fixed institutions in all German universities,- that usually one member of the seminary reported on certain scientific investigations which afterward were criticised and discussed, or investigations were undertaken in common, whereby the literature passed from hand to hand,- he suggests, regretfully, it would seem, that now obviously it is no longer possible to proceed in this way when, instead of the former ten or twenty members, from fifty to a hundred participate. "And that," he writes, "is now everywhere the case. Even in such a small university as Greifswald, I and some of my colleagues have had for a number of years in the neighborhood of, or over one hundred members in the seminary." "Confronted by this entirely different situation," he asks, "what is one to do?"

"But few teachers have the courage to simply shut the door 
when the original normal number of twenty of the select has been admitted. That would be at least consistent, though, to be sure, justified only if those excluded are certain of being taken in charge by other colleagues. . . . For the greater part one meets the situation by simply acting as if not a hundred but the modest circle of old were present and lets it go at that. Here and there perhaps one distinguishes between ordinary and extra-ordinary, or active and inactive members."

"Inactive members!" he exclaims, "the inner absurdity of the whole thing can scarcely be more plainly expressed: Ein inactiver Arbeitsunterricht!"

"There they sit, in the front ranks the few chosen actives with whose work the teacher is occupied, and the remainder, the great mass, sit behind and may listen. Whether or not they. are able to follow is not of the slightest consequence. - . Even if inclined that way, preparation for the topic under discussion even in a general way would be impossible since, as a rule, but one or two copies of the necessary books are to be found in the library. . . . Thus they sit there inactive in the true sense of the term; what they learn is more harmful than nothing: to squander their time in dull lethargy, - unless they prefer gradually to disappear. . . . But what of it? They have subscribed for their place in regular form and in their leaving certificates find gloriously certified that they have been members of the seminary."

Similarly, in medicine and in the natural sciences, the afflux to the laboratories is so great that larger lecture and work rooms have become a permanent need. In the largest universities the institutes for general anatomy, physiology, pathology, physics, chemistry, and other disciplines, have assumed extra-ordinary dimensions. Hundreds of students are accommodated and the rooms, as a rule, are filled to overflowing. Demonstrations in connection with lectures, because of the enormous size of the rooms, are practically impossible. Hence special demonstration rooms are provided, or opera glasses furnished to the students, or again, the desks are removed and the seats arranged in amphitheatrical fashion in order to shorten the air line between demonstration object and student.

In the laboratories, where make-shift methods would avail nothing since instruction of such masses of students by a single teacher is impossible, the attempt has been made to improve matters by dividing the attendance into groups, whereby instruction of the more advanced students is carried on by the director of the institute in person while the remainder, under his supervision, is left in charge of an assistant. But even this general supervision sometimes develops into a 
task beyond the power of one man and in that case the only alternative has been resorted to, namely, the establishment of a relatively independent division, whose head, however, with few exceptions is but an E.O. [Compare: (14).]

To multiply descriptions of this sort would serve no purpose. Enough has been said to show that there appears to exist some basis of truth for the claim of the N.O. that elimination of some of the difficulties under which instruction is carried on depends ultimately on a sufficient increase in the number of ordinary professorships.

\section{Why the Number of Ordinary Professorships Remains LIMITED}

The question arises: Why is there no adequate increase in the number of O.P., or, as the N.O. would put it; why are extra-ordinary professorships maintained in places where O.P. are necessary? As amplified by them, it is to be answered by saying that the blame rests foremost with the government. Economy, they suggest, surely is one reason. Expenses in behalf of the universities have in the last few decades grown enormously, amounting in 1908 in Prussia alone to about $\$ 4,250,000$, of which over $\$ 1,500,000$ went for salaries of teachers. Reason enough for economy, they say, and since the supply of teachers exceeded the demand, the State simply took advantage of the situation.

As a second reason for the retention of many E.O. in the subordinate position they advance a partly presumed, and partly demonstrated, policy of the State authorities to maintain as far as possible but one ordinary professorship in each one of the various departments of a faculty. This is done, they declare, to avoid friction which may result from a clashing of authority. But the principle of subordination is transferred automatically from the sphere of administration to the realm of the university where the lack of the spirit of colleagueship adds neither to the results of academic instruction nor to the dignity of the teaching profession.

Thirdly, it is asserted, in the filling of academic positions and in their gradation, a collateral factor has entered in the aim of the government to secure as strong a hold as possible upon the good will of the teaching force. There are nine distinct grades below that of the O.P. and, while it is not necessary to ascend the scale step by step, yet they present to the State a wealth of opportunities, by promotion now and then, to keep the teachers in good humor and earn their gratitude without much expense.

Last, but not least, the faculties are held to be responsible 
for the system of assistant teachers, "now in its fullest bloom." It is not difficult to appreciate the fact, they intimate, that the O.P. of a department, its only representative in the faculty, its recognized expert whose voice is decisive in all matters which concern it, after enjoying this perfect monopoly does not relish the idea of dividing his authority with another. In the capacity of director of an institute he likewise reigns alone, and as absolutely. What then is more natural, they ask, than that he, "a little czar in his dominion," hesitates to endanger his sovereignty by encouraging or expediting the advancement of a possible rival?

To attempt, from this distance, to sift the proverbial grain of truth from these contentions would be unprofitable. That the State, in so far as it is responsible for the system, has followed, as one writer puts it, "the principle of reasonableness in the economic rather than in the moral sense of the term," seems indeed reasonable. That occasionally personal considerations enter in determining a vote in the faculty is nothing strange to human nature. It is to be kept in mind, however, that the testimony emanates from not entirely disinterested sources.

\section{The Demands of the N.O. Analyzed}

As outlined by the Association of Prussian E.O., the following changes are called for: The "assistant-teachers" system should be abandoned and the principle established of filling only with O.P. all positions which represent a real teaching need. Accordingly, a majority of the E.O. should be promoted. The remainder should be granted a part in the corporate life of the universities commensurate with their importance for instruction and with their position as State officials. At greater detail, some of the following changes are held to be desirable:

(1) E.O. should have a vote in the election of the rector and of members of the senate. They should have representation in the administrative bodies of the university.

(2) E.O. should be kept informed of all faculty discussions which concern matters of instruction.

(3) An E.O. should have voice and vote in the faculty in all affairs which concern his department, whether in charge of an O.P. or not.

(4) E.O. should have equal rights with faculty members to act as referees of dissertations suggested by them, and as representatives of their department in the oral examinations.

(5) E.O. should have equal rights with the O.P. to the use of rooms and paraphernalia in the institutes and seminaries. 
(6) E.O. should receive a salary equal to that of other State officials of similar standing.

The petitions of the P.D., more moderate in nature as well as in language, call for an urgently needed increase in the number of positions for N.O.; a place in the discussions of university affairs; a hearing concerning their own affairs in future revisions of university and faculty statutes; and an opportunity to appear before the faculty and express an opinion in their own affairs, except where questions concerning promotion are involved.

Commenting first on the requests of the P.D., it is to be recalled that many help to swell the great body of N.O. though but loosely connected with the university. This is especially true of medical men, who, actuated sometimes by ulterior motives, have maintained their connection with the university though not exercising their right of docentship to a greater extent than was absolutely necessary. The opportunity for abuses rested in the fact that, except by disciplinary process, the venia legendi was inextinguishable. It was to be foreseen that efforts for reform would be directed first toward a possible weeding out of all undesirable elements. And that was precisely the course which the authorities pursued. The initiative for securing a legal basis for this process of house cleaning was taken by the philosophical faculty of the University of Berlin which, in 1911, by ministerial decree was empowered to amend the faculty statutes by inserting that "the venia legendi expires by waiver." Equal to a waiver is regarded (1) failure to announce lectures for two successive semesters, (2) unjustified failure to lecture during four consecutive semesters, (3) removal without special permit from the university city or its nearest suburbs, (4) acceptance of a major extra-academic position, except with the consent of the faculty. The lead of Berlin has been followed by other universities and amendments of the statutes are apt to be forthcoming where circumstances warrant a change. An objection to the regulations in their present form grows out of the fact that the venia legendi is presumed to expire automatically, so that a P.D. may be deprived of his right without being aware of it. An intentional indefiniteness of language, however, appears to allow the faculties great latitude in their decisions.

Concerning the request of the P.D. for an increase in the number of non-ordinary positions, there is no doubt that an official recognition of their work, though by nothing more than a teaching commission, would prove advantageous. By rendering possible a better organization of instruction, the establishment of introductory courses, the grading of seminaries and exercises, etc., a change in this direction might be beneficial. 
The arguments of the objectors can, for the most part, be reduced to an ignorance of conditions.

The plea of the P.D. for consideration in the event of future changes in the collegial organization of the universities is more apt to find favor. As integral parts of the teaching force they claim to be entitled to however a limited representation in the affairs of the university, and more particularly do they desire a share of the rights which the faculties exercise in their capacity as teaching bodies, for example, in the exam-. inations, the procuring of teaching material, construction of the lecture plan, etc. The Austrian P.D. for a long time have enjoyed some of the rights which are here petitioned for. In part they were also incorporated in some recently revised statutes of non-Prussian universities. With these precedents before them, the authorities may be expected in time to look more favorably upon such innovations.

Coming next to the demands of the E.O., it is to be admitted that their objective data constitute a not well disputable argument for the need of more ordinary professorships. But changes, as radical as the E.O. insist upon, are not easily brought about. The prevailing method of filling vacant chairs and creating new ordinary professorships takes into consideration the dual position of the universities so that the central and the academic authorities co-operate in the exercise of these functions. On part of the universities, the general statutes of the institutions as a rule impose upon the faculties the obligation "to provide for the completeness of instruction" and this includes the function, whenever the faculty feels that it is not strong enough to fulfil this obligation, to notify the ministry that it disclaims future responsibility in that respect, and to bring forward its detailed proposals. The faculty statutes usually provide, or when they do not, it is customary, for the faculties to propose three names for every vacant ordinary professorship. Of these the State authorities may recommend to the Sovereign the one best qualified for appointment or they may, if none seem suitable for the position, ignore them all. It will thus be seen that, when the E.O. assail the State's apparent trend to economy, they do not sufficiently appreciate that the establishment of new chairs does not involve merely the question of means for the larger salaries, and when, at the same time, they question the motives of the faculties, they attack in reality the whole system of appointment, - a system which, by means of the right of nomination by the faculties, furnishes a certain guarantee for the scientific ability of the candidate, tends to prevent the development of a ministerial absolutism, and serves as a protection against political pressure, while, by the fact that the final 
selection rests with the State, it acts as a check upon pernicious influences in the faculties; nepotism, sects and coteries, who might hold sway if they alone had the say in the appointments.

The lack of moderation of the E.O. is perhaps to be excused in view of the trying conditions developed by the fact that, judging by the past, it is unlikely that the authorities will consent to such a wholesale scheme of promotions as they propose.

In law, where the exigencies of the times call for a close alliance of the study of law proper with the newer science of the State and its foundations, the demand for the establishment of a faculty of political economy sometimes has been opposed by the faculty of law for no other reason than an assumed "numerous clausus" of the ordinary professorships.

In medicine where, in consequence of specialization, new departments grew up, the faculties refuse to acknowledge the importance of some of these and oppose the establishment of full professorships on the ground that they are subsidiary rather than independent departments, or on the ground that a change would involve the danger of a splitting of instruction and the certainty of adding to the difficulties of study and of examinations,- - reasons which, in the opinion of men qualified to speak, will not bear the test of closer scrutiny.

In the philosophical faculties, more particularly in the mental sciences, the ordinary chairs are not as well defined as in the upper three faculties. Here it happens that chairs hitherto filled by O.P., through the lack of a suitable successor, are temporarily given to an E.O., or extra-ordinary are changed into full professorships because only on that condition could a desirable successor be secured, or again, one chair for two equally important divisions of a science is occupied here by a representative of one branch, there, of the other. By this instability, since an increase in the total number of ordinary professorships is, as a rule, contrary to the wishes of the faculty, the causes for dissatisfaction naturally are multiplied and the filling of vacancies is apt to be accompanied by pointed discussions.

A recent incident of this sort brought to a point a crisis which has existed in a latent state for a number of years and which, since the whole episode is highly illustrative of the intricacies which surround the full professorship problem, deserves some space.

The philosophical chairs in most of the universities are occupied by professors of pure philosophy, so called, but in a few by psychologists. In the early part of 1913, a short time after the appointment of a psychologist to a chair of philosophy, a declaration, signed by 106 academic teachers, was 
sent to the faculties and administrative bodies of all German universities, protesting against the filling of chairs of philosophy with representatives of experimental psychology or men whose chief interests lie in that direction. During the infancy of this science, it was explained, the combining of the two disciplines in question under the charge of one O.P. was inevitable. But with the most gratifying rise of experimental psychology in late years its sphere of activity has grown so much that now for some time it is recognized as an independent science which demands the whole efforts of one teacher. Since the interest of academic youth in philosophy is likewise in the ascendant, the withdrawal from that science of chairs formerly dedicated to it exclusively is felt as a keen injury. In view of all this it would be to mutual advantage, and it is to be recommended, that experimental psychology have its own chairs in the future and that, wherever originally philosophical chairs are now held by psychologists, new professorships be established for the latter.

At first glance, the impartial care with which both branches are here provided for leaves the impression that motives only of a strictly objective nature guided the action of the signers of this declaration. The initiated, however, recognizes instantly the deeper significance of the procedure. Stated more succinctly, their purpose was to reclaim for philosophy all now existing ordinary professorships while suggesting that for psychology new chairs be established. Under the circumstances, pictured above, surely a strange way of balancing justice this which, as one writer puts it, "gives a hundred dollars to one, and promises them to the other." Excellency Wundt, with his intimate knowledge of conditions and his customary astuteness of analysis, did not take long in exposing the real issues of the case and pointed out that the ultimate result of a course as that proposed in the declaration would be the shifting off of experimental psychology into the natural sciences, more especially into the sphere of the medical sciences. "It's real meaning," said the historian Lamprecht, "when one penetrates through hides and tissues to the skeleton of this clever declaration, is nothing less than that so-called pure philosophy is set in array against the independent development of psychology within the frame of the philosophical sciences." "Out with the psychologists!" is the battle-cry.

And these charges some of the signers of the declaration do not at all deny. Psychology, Rickert and Natorp declare, by the introduction of experimental methods, has become a "Specialwissenchaft" which, adds Simmel, so far as he knows, "has produced nothing either positively or negatively of importance to specifically philosophical pursuits." 
To elaborate on the pros and cons of the argument is beyond the scope of this work. Enough has been said to show the precariousness, not to say hopelessness, of the cause of the E.O., when men of science, in order to gain their personal ends, do not hesitate to resort to intrigue for the purpose of influencing members of other faculties who are not familiar with inside conditions.

The attitude of the State toward the establishment of new chairs, on the other hand, is more likely determined by larger considerations than those attributed to it by the E.O. For it is hardly conceivable that the State, by condoning petty policies and devices, will incur the risk of impairing the efficiency of the universities,--those institutions who, by the power and extent of their influence, constitute one of its strongest pillars. The central authorities alone, owing to their advantageous position, are able to survey the university system of the Empire, and judge of its needs. The State, therefore, may be presumed often to be guided in its actions and policies by motives which to individuals or even to faculties remain obscure; yet make for the welfare of the system as a whole.

In the matter of an enhancement of their rights in affairs of administration and instruction the efforts of the E.O. are apt to be crowned by better success. With the general decree of 1910 for all Prussian universities as an entering wedge, with a precedent established in recently revised statutes of several universities, and with the organization of the professor-collegium in the Austrian institutions as a model, they enjoy in addition the advantage of having the best of the argument.

\section{Some Recent Reforms}

Aside from the new salary regulations for Prussia of April 1,1909 , the organized efforts of the E.O. thus far have produced but one more general result in the Prussian royal decree of May 30, 1910, already referred to, which provides that etatsmässige E.O., active in a special discipline not represented in their faculty, have a seat and decisive vote in that faculty in all matters related to that special discipline. The decision of the question as to which disciplines are to be regarded as special ones is made to rest with the minister of education. It provides further that the right to elect the rector from the midst of the O.P. henceforth be extended to the E.O. with the restriction, however, that the total number of the E.O. qualified to vote must not exceed one half of the total number of the O.P. The right of the E.O., when a limitation of their number becomes necessary, is to be determined by seniority. 
In the non-Prussian universities, more notable concessions have been made.

(1) The general statutes of the University of Jena, published in 1907, provide that H.P., E.O., and P.D., if necessary, may be called upon to give opinions, judge dissertations, and take part in examinations, in which case they are entitled to a vote and to a share of the fees.

(2) In the new statutes of the University of Tübingen, "revised in accordance to the spirit of the times," and published in 1912, the N.O. receive consideration to the following extent:

(a) Three N.O., elected for a term of three years, are entitled to a seat in the larger Senate, and one N.O. in the smaller Senate.

(b) All H.P. and E.O. in charge of a special discipline or of an institute, are entitled to a seat in the Professorcollegium in all matters concerning their departments, inclusive of promovations. Other H.P. and E.O., with the permission of the ministry, may also be given seat and vote in the faculty.

(c) N.O. are excluded from deliberations concerning the filling of vacant ordinary chairs, but may be consulted by the faculty.

(d) H.P. and E.O. take part in the election of the rector, but their number is restricted to one half the number of the O.P.

(e) All teachers outside the collegium have the right to be heard in their own affairs when they concern their person or their activity as teachers.

(f) N.O. are eligible to membership of committees of the smaller Senate, if appointed for the transaction of special business.

(g) For purposes of consultation, N.O. may be requested to attend meetings of the faculty and of the larger Senate.

(h) Records of the proceedings of the smaller Senate are open for inspection to N.O. members of the larger Senate.

(3) By ministerial decree of April 24, 1913, H.P. and E.O. of the University of Jena are accorded the right to participate in the election of the prorector, but with the restriction as to number in vogue in the Prussian universities. The N.O., furthermore are entitled to representation in the Senate by a committee of three, which takes part in the deliberations concerning their interests but has no decisive vote.

(4) In the University of Freiburg, in 1913, H.P. were granted the right to co-operate in the election of the prorector, 
with restrictions as to number. The resolve further provided that every teacher should be made acquainted with all decrees of the administrative bodies which affect the common interests of the teaching force.

(5) In the three Bavarian universities, Munich, Würzburg, and Erlangen, where for sometime N.O. have co-operated in the election of the rector, a royal decree of July 22, 1913, granted them additional rights as follows:

(a) E.O. in a special discipline, or when directors of an institute, have a seat and vote in the faculty in all matters concerning their discipline or institute, promovations included; excepted are matters concerning the filling of chairs other than those of extra-ordinary professorships.

(b) The faculty may invite for consultation teachers or offcials who are not members of the faculty in the narrow sense of the term. With the consent of the faculty, the dean may empower teachers outside of the faculty to report on faculty affairs, and they shall then have a decisive vote in the matter. Such matters are, more especially, promovations.

(c) Every teacher has the right to be heard in his own affairs concerning his person, his teaching activity, or the institute directed by him, except concerning vacancies, promotions, and teaching commissions.

(d) At least once during the academic year, and further upon the request in writing of ten teachers, the dean shall call a meeting of the faculty in the wider sense of the term. At this meeting, wishes and suggestions in faculty affairs shall be in order, all except those concerning vacancies, promotions, and teaching commissions.

\section{The New Universities}

The new University of Frankfort, the Göthe University, as some propose to call it, has introduced in its general statutes, so far as the rights of the N.O. are concerned, but one innovation. As in all other Prussian universities, the E.O. co-operate, with numerical restrictions, in the election of the rector and have voice and vote in the faculties in all matters concerning a special discipline not otherwise represented. But in addition they are given some representation in the administrative affairs of the university in the form of an E.O. who is elected annually to membership of the academic Senate.

In the matter of faculties and the make-up of its governing bodies the university presents some unique features. The theological faculty is conspicuous by its absence. On the other 
hand, the new university stands alone in having a "Wirtschafts- und Socialwissenschaftliche Facultät," a faculty of sociology or " Kulturwissenschaft."

The regulations governing the composition of the chief administrative body of the university are unusual in two respects. They expressly state that all professors and P.D. are ineligible to membership of the Great Council, with the exception of the rector and the prorector, who are members ex-officio. The deans may be called in when faculty business is to be considered and in that case have voice and vote. The State, likewise, has no representative in this body. The Council is distinctly municipal in its membership. Then again, in a second, smaller body, "the Curatorium," the teaching force of the university as such has absolutely no share in the administration of the university. Frankfort, accordingly, closely approaches the system which prevails in American universities where the president, as a rule, is the only representative of the university in its governing board.

Two other German cities are contemplating the establishment of a municipal university, namely, Hamburg and Dresden. Of these, the plan of Dresden is in its primary stages and, in view of strong opposition by the University of Leipsic, is likely to remain there for some time to come. In Hamburg better progress has been made and the plan for the new university has taken more definite shape. It is proposed for the present to omit faculties of theology and medicine but to introduce an innovation in the form of a faculty for Colonial Sciences.

Concerning the teaching staff, the Prospectus states that E.O. for remote and special disciplines are considered still necessary, but only salaried E.O., with an annual salary ranging from $\$ 1,250$ to $\$ 2.250$ and all lecture fees in full, will be appointed. They are to have a seat and vote in the faculty even though their discipline is represented by an O.P. With a restriction as to number they will be entitled to take part in the election of the rector, and they are to have additional representation in the administrative affairs of the university in a new body to be known as Professorial Council.

But all these plans, like many others, it is sad to recollect, may be upset by the work of that grim reaper who just now stalks about Europe's blood-stained battle-fields, and who knows no distinctions between E.O and O.P.*

* The following statistics, compiled by the writer from authentic sources, will serve to give an indication of the effect of the war on the universities: 
Total number of students enrolled in all German universities :

Summer Semester 19r4............................ 61254

Winter Semester 1914-15....................... 52547

Of these in military service, 30104.

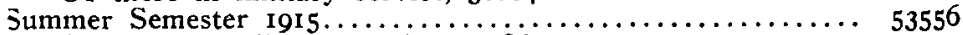

Of these in military service, 34386 .

Total number of active academic teachers: (exclusive of H.P.)

March 19r4................. I197 O.P., 740 E.O., I250 P.D.

August $1915 \ldots \ldots \ldots \ldots \ldots \ldots \ldots \ldots \ldots \ldots \ldots \ldots$ 1250 O.P., 801 E.O. I201 P.D.

Of the latter, in military or auxiliary service in 1915/16: 205 O.P., 269 E.O., 551 P.D., distributed among the faculties as follows :

Theology $\ldots \ldots \ldots$. 9 O.P. of $18 \mathrm{r}, \quad 7$ E.O. of 50 , II P.D. of 52 Law $\ldots \ldots \ldots \ldots \ldots, 35$ O.P. of 188,16 E.O. of 55, 26 P.D. of 68 Medicine .......... 8I O.P. of 247, I46 E.O. of 29I, 30I P.D. of 520 Philos., Nat. Sci... 80 O.P. of 634, I00 E.O. of 405, 213 P.D. of 56r

Number of deaths on the battle-field:

Winter of 19r4-15................ 6 O.P., 3 E.O., 6 P.D.

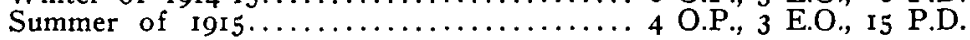

A notable fact is the steady increase in the number of women-students. There were enrolled in all German universities :

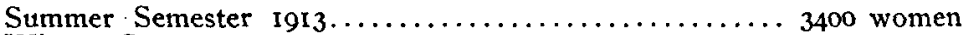
Winter Semester $1914-15 \ldots \ldots \ldots \ldots \ldots \ldots \ldots \ldots \ldots \ldots \ldots \ldots . \ldots . \ldots \ldots 20$ women Summer Semester I9I5................... 4569 women

the latter distributed among the faculties as follows: Theology, 7; Law, 116; Medicine, 1,189; Philosophy and the Natural Sciences, 3,225. (Not known, 32.)

\section{BibliogRAPHY}

I. Beer, Ludwig. Der deutsche Hochschullehrertag. Akadem. Rundschau, December 1913, vol. 2, No. 3, pp. 122-134.

2. Bernheim, ERnst. Zwei Vorträge. Ernst Wiegandt. Leipzig, I9I2. 74 p.

3. Bornhak, Conrad. Die Rechtsverhältnisse der Hochschullehrer in Preussen. Georg Reimer. Berlin, I90I. 104 p.

4. Damman, Walter E. Die Lehrtätigkeit der Privatdozenten. Akadem. Rundschau, December 1912, vol. I, No. 3, p. 170-174.

5. Eulenburg, Franz. Der akademische Nachwuchs. B. G. Teubner. Leipzig und Berlin, I908. I55 p.

6. Hillebrand, Franz. Die Aussperrung der Psychologen. Zeits. f. Psy. I9r3, vol. 67, pp. I-21.

7. Hoeser, Karl. Das deutsche Universitäts- und Hochschulwesen. Kösel. Kempten und München, 1912. $297 \mathrm{p}$.

8. Lamprecht, Kart. Zwei Reden zur Hochschulreform. Weidemann. Berlin, I910. $45 \mathrm{p}$. 
9. - Eine Gefahr für die Geisteswissenschaften. Die Zukunft. April 5, I9r3, vol. 83, pp. 16-24.

10. NaUmanN, VictoR. Die deutschen Universitäten in ihrem Verhältnis zum Staat, ihre Verfassung und Verwaltung, ihre Statuten und Disziplinar-Ordnungen. Styria. Graz und Wien, I909. p. 73.

I I. Printz, Wilhelm. Der Hamburger Universitätsplan. Akadem. Rundschau, Febr. I9ı3, vol. I, No. 5, pp. 268-277.

12. ...... Verhandlungen des ersten deutschen Hochschullehrertages. Karl J. Truebner. Strassburg, I908. $66 \mathrm{p}$.

I3. Vorstand der Vereinigung ausserordentlicher Professoren Preussens. Die Lage der ausserordentlichen Professoren an den preussischen Universitäten. Creutz. Magdeburg, I9II. II2 p.

14. Waintig, Heinrich. Zur Reform der deutschen Universitäten. Verlag der Grenzboten. Berlin, I9II. 49 p.

15. Wundr, Wilhelm. Die Psychologie im Kampf ums Dasein. Alfred Kröner. Leipzig, I9r3. 38 p. 